\title{
Der Kanon
}

\section{Erhard Taverna}

Dr. med., Mitglied der Redaktion

Thomas Kersten, Bildungsredakteur der ZEIT, hat es gewagt, Bildungsinhalte zu benennen. Sein Buch «Was unsere Kinder wissen müssen - ein Kanon für das 21. Jahrhundert» wurde erwartungsgemäss kontrovers aufgenommen. Viel Zustimmung für die hundert Werke aus Musik, Mathematik, Malerei, Literatur und Naturwissenschaft, aus Geschichte, Philosophie und Politik. Viele Bücher, aber auch Filme, TV-Serien, Gemälde und Fotos. Allen recht getan ist eine Kunst, die niemand kann. Ein Kanon, der sich auf männliche, weisse Stimmen konzentriere sei fragwürdig, es fehlten die Frauen, Farbige, Queers und Angehörige anderer Randgruppen. Für jemanden, dem viel an einem gemeinsamen Fundament, am Kitt liegt, der die Gesellschaft zusammenhält, bestätigt die Kritik das Vorhaben eine sterile Bildungsdebatte mit Inhalten zu füllen, wie es der Autor hervorhebt.

Am Rande des bekiesten, von Kastanienbäumen umgebenen Pausenplatzes plätscherte ein Brunnen. Ein bronzener Chiron unterrichtete Achill, der sitzend den linken Oberarm auf dem Rücken des Kentaurs abstützte. Das heilkundige Mischwesen hatte schon viele berühmte Männer erzogen. Mag sein, dass dieses Werk von Alexander Zschokke (1894-1981) dem Unterricht als Vorbild diente. Auf der Wandtafel im Klassenzimmer war der göttliche Stammbaum aufgezeichnet. Chiron, dem Sohn des Kronos, des Gottes der Zeit, verdankte Asklepios seine ärztliche Kunst. Beim Altgriechen ging es um Mord, Sex, Betrug, Inzest und Heldentaten, beim Lateiner wurde Gallien erobert und es war süss für das Vaterland zu sterben, der Religionslehrer warnte vor zu früher Liebe. In allen Fächern waren gute Noten erwünscht. Der Schüler Achill war ein Rambo des troja-

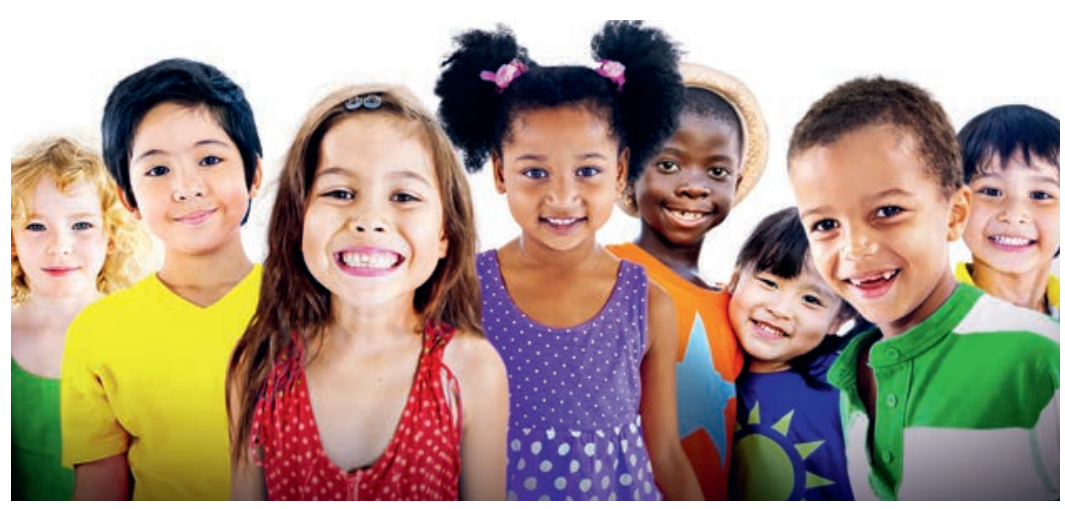

nischen Krieges. Berge von Leichen und gebrochene Frauenherzen. Vielleicht hatte er nach dem falschen Kanon gelernt.

Ein Kanon bezeichnet die auserwählten Werke, das, was dogmatisch richtig ist. Anläufe zu weltlichen Listen exemplarischer Werke hat es immer wieder gegeben. Hitparaden ihrer jeweiligen Zeit. Sie sollen einen Wertekonsens vermitteln, eine Grundlage für Debatten, einen allseits bekannten Fundus von Bildern, Erzählungen und Musikstücken. Je fragmentierter eine Gesellschaft ist, je mehr Menschen sich ausschliesslich in ihren Echokammern aufhalten, desto hitziger die Bildungsdiskurse. Für den deutschen Sprachraum hat der Literaturkritiker Marcel Reich-Ranicki, vor bald zwanzig Jahren, mit einer Anthologie unumgänglicher Bücher dagegengehalten. Wenn Bildung etwas mit der Entwicklung von Persönlichkeit zu tun hat, wird auch die Digitalisierung nichts daran ändern. Zur Arbeit mit Normen und Standards gehört die Auseinandersetzung mit Texten und Theorien. Ohne Anstrengung geht nichts, doch gemäss Ranicki darf die Literatur auch Spass machen. Die Rede ist von kulturellen Leitplanken, von einem gemeinsamen Bezugsrahmen, von Inklusion und Identität. Anspruchsvoller als der Entschluss des Bayerischen Landeskabinetts, in jeder Behörde ein Kreuz aufzuhängen. Ein Kanon ändert sich mit jeder Generation, einiges hat Bestand, vieles verschwindet. In allen Darstellungen werden immer Menschen sich selber finden, ein Abbild dessen, wie sie die Welt sehen und erleiden. Messen lässt sich das unter anderem an der Wirkungsgeschichte von Büchern, wie sie beispielhaft der Historiker Urs Bitterli in seiner Kulturgeschichte «Licht und Schatten über Europa 19001945» erzählt. Ein Kanon der anderen Art, fünfzig Publikationen, die zu ihrer Zeit Millionen Menschen beeinflusst haben. Spiegel einer turbulenten Epoche, in der viel Kanonisches, das lange Zeit unverzichtbar schien, zugrunde ging.

\section{Referenzen}

- Kerstan T. Was unsere Kinder wissen müssen, ein Kanon für das 21. Jahrhundert. Hamburg 2018, Edition Körber

- Bitterli U. Licht und Schatten über Europa 1900-1945. Verlag Neue Zürcher Zeitung 2016

Bildnachweis

(C) Rawpixelimages | Dreamstime.com 